\title{
Investigation of Corrosion Behavior of X65 Steel in Simulated Deep-Sea Environment Using Electrochemical Techniques
}

\author{
Qiushi Li ${ }^{1,2,3}$, Bingchuan Guo ${ }^{1,4}$, Bing Sun ${ }^{5}$, Jihui Wang ${ }^{2, *}$, Xin Liu $^{2}$ \\ ${ }^{1}$ CCCC Tianjin Port Engineering Institute Ltd., Tianjin, 300222, P R China \\ 2 Tianjin Key Laboratory of Composite and Functional Materials, School of Materials Science and \\ Engineering, Tianjin University, Tianjin, 300072, P R China \\ ${ }^{3}$ CCCC First Harbor Engineering Company Ltd., Tianjin, 300461, P R China \\ ${ }^{4}$ Offshore Engineering Technology Center, China Classification Society, Tianjin, 300457, P R China \\ ${ }^{5}$ CenerTech Oil Production \& Service Company, Tianjin, 300452, P R China \\ *E-mail: qsli@tju.edu.cn (Qiushi Li), jhwang@tju.edu.cn (Jihui Wang)
}

doi: $10.20964 / 2021.05 .05$

Received: 2 December 2020 / Accepted: 8 February 2020 / Published: 31 March 2021

The corrosion behaviors of X65 steel in the simulated deep-sea environment at different temperatures are investigated using electrochemical techniques. The effect of temperature on corrosion products are also analyzed by X-ray diffraction. The results indicate that the corrosion current density decreases as the temperature decreases. The polarization resistance increases as the temperature decreases. The composition of the corrosion products formed on the surface of X65 steel remains the same as the temperature decreases, mainly composed of $\gamma-\mathrm{FeOOH}, \gamma-\mathrm{Fe}_{2} \mathrm{O}_{3}$, and $\mathrm{Fe}_{3} \mathrm{O}_{4}$. The low temperature in the deep-sea environment retards the corrosion of X65 steel by inhibiting the anodic dissolution reaction.

Keywords: X65 steel, Deep-sea environment, Temperature, Electrochemical techniques, Corrosion

\section{$\underline{\text { FULL TEXT }}$}

(C) 2021 The Authors. Published by ESG (www.electrochemsci.org). This article is an open access article distributed under the terms and conditions of the Creative Commons Attribution license (http://creativecommons.org/licenses/by/4.0/). 